\title{
A retrospective study to evaluate etiological factors associated with intrauterine fetal death at tertiary referral centre
}

\author{
Shweta Patel ${ }^{1} *$, Manik Sirpurkar ${ }^{1}$, Meghraj Singh Patel ${ }^{2}$ \\ ${ }^{1}$ Department of Obstetrics \& Gynaecology, Chirayu Medical College \& Hospital, Bhopal, M.P., India \\ ${ }^{2}$ Department of Medicine, Chirayu Medical College \& Hospital, Bhopal, M.P., India \\ Received: 29 February 2016 \\ Revised: 08 March 2016 \\ Accepted: 10 March 2016 \\ *Correspondence: \\ Dr. Shweta Patel, \\ E-mail: drshwetayadavmd@gmail.com \\ Copyright: ( $\odot$ the author(s), publisher and licensee Medip Academy. This is an open-access article distributed under \\ the terms of the Creative Commons Attribution Non-Commercial License, which permits unrestricted non-commercial \\ use, distribution, and reproduction in any medium, provided the original work is properly cited.
}

\begin{abstract}
Background: Amongst various community health indicators available for measurement of quality and impact of health services in developing countries, perinatal mortality finds its position as being one of the top most single indicators even today. In order to have a decrease of the fetal mortality rate, it is necessary to know the etiology of fetal death and its associated risk factors in different populations. Thus the purpose of this study was to investigate about the prevalence, patient profile, socio-demographical and etiological risk factors associated with fetal losses beyond 24 weeks of pregnancy in our hospital.

Methods: This study was conducted at Chirayu Medical College \& Hospital, Bhopal, India. Retrospective data of all the cases with $\geq 24$ weeks gestation with intrauterine fetal death, admitted in the study period (November 2010December 2015) were collected $(n=51)$. All socio-demographic, antenatal and intrapartum risk factors associated with IUFD were recorded in proforma and statistical analysis done.

Results: Total numbers of births in the study period were 1410, out of which fetal losses beyond 24 weeks of gestation occurred in 51 cases. This gave the perinatal mortality rate for our hospital as 36.17/1000 live births. This rate is much more than the national figure quoted by the central government in 2012 as $28 / 1000$ live birth. Hypertensive disorders of pregnancy were the most commonly responsible factor $(27.45 \%)$ in the study group followed by congenital malformations $(9.80 \%)$. In $11.76 \%$ cases cause was not explained.

Conclusions: It is a well-established fact that adequate antenatal care is associated with better pregnancy outcome, but universal antenatal care is not the protocol in our area, reasons being ignorance, illiteracy, lack of awareness of importance of antenatal care, poverty and non-availability of health care facilities/skilled personnel/infrastructure/transport. Health education and emphasis on the need of each and every delivery being institutional under supervision of appropriate personnel needs to be propagated in the community aggressively. This only will help in reducing a number of preventable fetal deaths and huge loss of our national assets.
\end{abstract}

Keywords: Intrauterine fetal death, Fetal demise, Still born

\section{INTRODUCTION}

Perinatal mortality (PNM) is the single best community health indicator available to measure quality of health services in any community. ${ }^{1}$ Intrauterine fetal death (IUFD) as per WHO definition considers any abortion or fetal demise prior to expulsion from mother's body with varying gestational period, while still birth as defined by $\mathrm{WHO}$, is the fetal death in late pregnancy. ${ }^{2}$ There are wide differences in the definition of IUFD in relation to gestational period among various academic groups like perinatal mortality surveillance report (PMSR), ACOG, recent clinical practice investigation guidelines (RCPI) and so on. We have used for our study, RCPI guideline 
for defining IUFD, as death of fetus inutero after 24 weeks of pregnancy. ${ }^{2}$

Perinatal mortality rate (PNMR) is defined as fetal death in utero beyond 28 weeks of antenatal, intrapartum period or postnatal period up to 7 days after birth. The rate of perinatal mortality as per Indian census of 2012 was $35 / 1000$ and still birth rate was 6/1000 live births for the state of Madhya Pradesh. ${ }^{3}$

In recent years significant decline is achieved in PNM due to significant decrease in intrapartum fetal loss but correspondingly ante partum fetal loss still has remained unaffected. As estimated $10-15 \%$ of all recognized pregnancies end in unexpected loss.

Various methods of classifying the causes of fetal death are in use today like Tulip, extended Wigglesworth, modified Aberdeen, Re Co De, PSANZ-PDC classification. $^{4-6}$ Still in many of IUFD cases, cause remain unexplained and hence unclassified. We should always try to identify the cause so as we are able to counsel and consol the grieving family properly and also help in taking adequate measure of to prevent loss in future.

In our hospital the obstetrics work received mostly unbooked type or referred from surrounding rural and semirural areas after complications had set in. So relatively we find both maternal and perinatal morbidity and mortality on higher side and frequent.

This study gave us an insight into the extent of obstetric care available, nature of mismanagement, treatable and preventable reasons for intrauterine fetal death. We also came to know about the policies to be adopted and implemented at our sub centres at periphery catering to rural population and hospital to reduce the perinatal mortality in this area.

\section{Aims \& objectives}

The aim of this study was to find the incidence and characteristics of pregnancies that resulted in IUFD in our surroundings with the following objectives:

1. To identify risk factors associated with intrauterine fetal death.

2. To emphasize the need of antenatal supervision; identify the complications at the earliest \& manage them. 3 . To emphasize the need of early referral.

\section{METHODS}

The study was conducted at Chirayu Medical College \& Hospital, Bhopal, India. Retrospective data of all the cases of Intrauterine fetal death (antepartum or intrapartum) admitted in the study period (November 2010-December 2015) were recorded $(n=51)$. In all antenatal cases with gestational age $\geq 24$ weeks with IUFD (diagnosed by absent of heart sound and further confirm by ultrasonography), complete history and investigations were recorded to find relevant antenatal and/or intrapartum causes leading to IUFD. Placenta and cord examination after delivery were performed in all cases. Autopsy was declined by majority of the relatives, so only gross examination of fetus was done to note congenital malformation if any.

Following parameters were recorded in proforma after approval obtained from research and ethical committee of our institute.

Women's age, parity, socioeconomic status, booked/referral cases, spontaneous conception or conception after infertility treatment, any complaint during present pregnancy, history of IUFD in past pregnancy, complaint/diagnosis at the time of admission, gestational age, past and present medical disorders, history of pregnancy related or aggravated conditions, mode of delivery, any intra or postpartum complications. Relevant investigations to define cause of IUFD were also noted.

Data was compiled and analyzed statistically by using simple statistical measures like percentage \& proportions in view of the aim and objectives.

\section{RESULTS}

Total numbers of births in our study period were 1410 , out of which 51 were IUFD or still birth. The incidence of IUFD in our study was $36.17 / 1000$ live birth.

As shown in Table 1, maximum number of IUFD occurred in primigravida $(47.05 \%)$. Lower socioeconomic status was noted in $58.80 \%$, with $39.21 \%$ cases in 21-25 year age group. Most cases were unbooked $(49.01 \%)$ or referred $(45.09 \%)$ from periphery and surrounding hospitals. Maximum cases conceived spontaneously $(98.01 \%)$, only one case of IUFD occurred in a patient who conceived after infertility treatment. Maximum IUFD occurred at term (35.29\%).

As mentioned in Table 2, maternal risk factors were noted in $52.91 \%$ cases, out of which hypertensive disorder in pregnancy $(27.45 \%)$ was the most common cause of IUFD. Fetal risk factors were found in $11.76 \%$ cases, in which congenital malformation $(9.80 \%)$ were the most common association. Placental risk factors were noted in $16.56 \%$ cases. In $11.76 \%$ cases cause was not explained.

As depicted in Table 3, most cases of IUFD came in late labor and delivered vaginally (41.17\%), while $23.52 \%$ cases were delivered after induction of labor. Out of all IUFD, $82.35 \%$ were fresh and $17.64 \%$ cases showed retroplacental clots after placental examination. 
Table 1: Depict demographic and clinical profile (maternal characteristics) of the cases under study.

\begin{tabular}{|c|c|c|c|}
\hline Age group & Number $(\%)$ & Booking Status & Number $(\%)$ \\
\hline$\leq 20$ years & $03(5.88)$ & Booked & $03(5.88)$ \\
\hline $21-25$ & $20(39.21)$ & Unbooked & $25(49.01)$ \\
\hline $26-30$ & $18(35.29)$ & Referred & $23(45.09)$ \\
\hline $31-35$ & $07(13.72)$ & Conception & Number (\%) \\
\hline$\geq 35$ years & $03(5.88)$ & Spontaneous & $50(98.01)$ \\
\hline Parity & Number (\%) & Induced & $01(1.96)$ \\
\hline $\mathrm{G}^{* 1}$ & $24(47.05)$ & POG* at diagnosis & Number $(\%)$ \\
\hline G2 & $12(23.52)$ & $\leq 28$ weeks & $11(21.56)$ \\
\hline G3 & $10(19.06)$ & $28-32$ & $14(27.45)$ \\
\hline$\geq \mathrm{G} 4$ & $05(9.80)$ & $33-36$ & 07 (13.72) \\
\hline SES $* * * 7$ & Number (\%) & $37-40$ & $18(35.29)$ \\
\hline Lower & $30(58.80)$ & $\geq 40$ weeks & $01(1.96)$ \\
\hline Middle & $19(37.25)$ & \multirow{2}{*}{ H/O IUFD in past pregnancy } & Number (\%) \\
\hline Upper & $02(3.92)$ & & $04(7.84)$ \\
\hline
\end{tabular}

$* \mathrm{G} \cong$ Gravida, $* * \mathrm{POG} \cong$ Period of gestation, ***SES: Socioeconomic status as per KuppuSwami classification ${ }^{7}$

Table 2: Showing clinical risk factors associated with the cases under study.

\begin{tabular}{|c|c|c|c|c|c|}
\hline \multicolumn{2}{|c|}{ Risk Factors } & \multicolumn{2}{|l|}{ Number (\%) } & \multirow{2}{*}{$\begin{array}{l}\text { Risk Factors } \\
\text { Severe IUGR }\end{array}$} & \multirow{2}{*}{$\begin{array}{l}\text { Number }(\%) \\
1(1.96)\end{array}$} \\
\hline M & Preeclemptic toxemia & & \multirow{3}{*}{ Fetal } & & \\
\hline \multirow[b]{2}{*}{$\mathbf{A}$} & Severe preeclempsia & $8(15.60)$ & & Congenital malformations & $5(9.80)$ \\
\hline & Eclempsia & $6(11.76)$ & & Total & $6(11.76)$ \\
\hline \multicolumn{3}{|c|}{ Labor complications } & \multirow{7}{*}{ Placental } & Postdatism & $1(1.96)$ \\
\hline $\mathbf{T}$ & Head arrest & $2(3.92)$ & & Abruption & $2(3.92)$ \\
\hline \multirow{2}{*}{$\mathbf{E}$} & Ruptured uterus & $3(5.88)$ & & Placenta previa & $1(1.96)$ \\
\hline & Medical disorders & & & $\mathrm{PROM}^{* *}$ & $2(3.92)$ \\
\hline \multirow{2}{*}{$\mathbf{R}$} & Gestational DM* & $1(1.96)$ & & PPROM*** & $2(3.92)$ \\
\hline & Hypothyroidism & $1(1.96)$ & & Severe oligohydramnios & $1(1.96)$ \\
\hline \multirow[t]{2}{*}{$\mathbf{N}$} & Jaundice & $4(7.84)$ & & Total & $9(16.56)$ \\
\hline & Complicated malaria & $1(1.96)$ & \multirow{3}{*}{ Others } & Retained twin & $1(1.96)$ \\
\hline \multirow{3}{*}{$\begin{array}{l}\mathbf{A} \\
\mathbf{L}\end{array}$} & Severe anemia & $1(1.96)$ & & Severe burn & $2(3.92)$ \\
\hline & Total & $27(52.9)$ & & Total & $3(5.88)$ \\
\hline & Unexplained & & $6(11.76)$ & & \\
\hline
\end{tabular}

*Gestational Diabetes Mellitus, \# Intrauterine Growth Retardation, **Premature Rupture of Membrane,*** Preterm Premature Rupture of Membrane

Table 3: Showing fetal characteristics, mode of delivery and placental findings of the cases under study.

\begin{tabular}{|c|c|c|c|}
\hline Mode of delivery & Number(\%) & Placental Examination & Number(\%) \\
\hline Vaginal & $33(64.70)$ & Normal & $40(78.43)$ \\
\hline Spontaneous & $21(41.17)$ & Retroplacental clots & $9(17.64)$ \\
\hline Induced & $12(23.52)$ & Adhered placenta & $2(3.92)$ \\
\hline Vaginal breech extraction & $5(9.80)$ & Fetal morphology & Number (\%) \\
\hline Cesarean section & $9(17.64)$ & Fresh & $42(82.35)$ \\
\hline Hysterotomy & $1(1.96)$ & Macerated & $9(17.64)$ \\
\hline Laprotomy & $3(5.88)$ & \multirow{2}{*}{ Fetal congenital malformations } & Number (\%) \\
\hline Fetal sex & Number $(\%)$ & & $9.80 \%$ \\
\hline Male & $29(56.86)$ & CNS malformations & $4(7.84 \%)$ \\
\hline Female & $22(43.33)$ & Multiple organs malformations & $1(1.96 \%)$ \\
\hline
\end{tabular}


As shown in Table 4, PPH occurred in 12 (23.52\%) cases, out of which $10(9.60 \%)$ cases required blood transfusion. There were four cases of maternal mortality observed in our study group.

Table 4: Showing puerperal complications in cases under study.

\begin{tabular}{|ll|}
\hline Puerperal complications & Number $(\%)$ \\
\hline Breast engorgement & $14(27.45)$ \\
\hline Psychological upset & $29(56.86)$ \\
\hline Puerperal infections & $7(13.72)$ \\
\hline Post-partum haemorrhage & $12(23.52)$ \\
\hline Manual removal of placenta & $2(3.92)$ \\
\hline Blood transfusion & $10(19.60)$ \\
\hline Maternal mortality & $4(7.84)$ \\
\hline
\end{tabular}

\section{DISCUSSION}

Death of a viable fetus is a distress to the family and the obstetrician both for a long time in life. Despite advances in medical science, availability of diagnostic and therapeutic modalities, pregnancy wastage still occurs and recurs, at an unacceptably high rate. Although the perinatal mortality has reduced over last few decades, the intrauterine fetal deaths still remain exceptionally high. ${ }^{8}$

The incidence of IUFD in our study was found to be $36.17 / 1000$ live births, In the study from upper part of India conducted by Singh $\mathrm{N}$ et $\mathrm{al}^{9}$ incidence was 40/1000, while in the study conducted by Patel $\mathrm{S}$ et al ${ }^{10}$ incidence was 22.2/1000 live birth. Rate of stillbirths vary greatly in different studies and regions. A study from Faridkot, India, quotes a very high still birth rate of 125 per 1000 live births. ${ }^{11}$

In our study, maximum cases of IUFD occurred in primigravida i.e. in $47.05 \%$ while in study by Patel S et $\mathrm{al}^{10}$ proportion of IUFD was higher i.e. $60 \%$ in multigravidae cases. We found only five IUFD $(9.80 \%)$ in multigravidae cases. Study by Tariq et $\mathrm{al}^{12}$ had not found any association between parity and gestational age. Maximum IUFD cases were belonged to 21-25 years $(35.2 \%)$, same as study by Patel S et al ${ }^{10}$ while Tamarkar $\mathrm{SR}^{13}$ had reported higher stillbirth associated with increasing maternal age.

Our majority of cases belonged to low socioeconomic status $(58.80 \%)$ and either referred from periphery $(45.09 \%)$ or unbooked came in emergency $(49.05 \%)$. We had only three booked cases with IUFD (5.88\%). Observations are supported by studies by Patel $\mathrm{S}$ et al, ${ }^{10}$ Korde NV et al ${ }^{14}$ and Anjali $\mathrm{C}$ et al. ${ }^{8}$ They had founded $70 \%, 84.9 \%$ and $89.5 \%$ IUFD cases in unbooked admission respectively. As our hospital is a tertiary care hospital we mostly admitted referred cases with severe maternal morbidity without appropriate antenatal care, cases in late stage of labor or when IUFD was diagnosed by USG.
Our cases mostly had conceived spontaneously, only one case had conceived after infertility treatment (post IVF conception). This patient had term IUFD and cause was unexplained. Majority (35.29\%) of IUFD occurred in 3740 weeks of gestation same as in study by Singh $\mathrm{N}$ et $\mathrm{al}^{9}$ and mentioned that uterine condition become hostile at this period and therefore it is recommended to have closed surveillance at 37 weeks and beyond.

Most common maternal risk factor for IUFD in our study was hypertensive disorders in pregnancy i.e. eclampsia $(11.76 \%)$ and severe preeclampsia $(15.60 \%)$. Singh N et $\mathrm{al}^{9}$ had observed the same in $10.81 \%$ while Patel S et al ${ }^{10}$ observed it in $33.7 \%$ cases.

As our institute is a tertiary care centre surrounded by the rural area, where many women are still delivered at home by untrained dais, people are uneducated belonging mostly to lower class and with no concept of antenatal care. We received many obstetric cases with complicated medical disorders or cases with labor complications like cases of severe jaundice $(7.84 \%)$, pregnancies with breech presentation with head arrest $(3.92 \%)$, cases of obstructed labor followed by ruptured uterus $(5.88 \%)$, uncontrolled GDM (1.96\%), severe anemia (1.96\%), complicated malaria $(1.96 \%)$ and uncontrolled hypothyroidism $(1.96 \%)$. It is well established fact that adequate ANC is associated with better pregnancy outcome. ${ }^{15}$ Anjali $\mathrm{C}$ et $\mathrm{al}^{8}$ mentioned in her study that proper antenatal care, recognition of risk factors appropriate management, judiciously timed delivery, intra partum monitoring and timely intervention has reduced the incidence of IUFD resulting from these factors. We also found that these are the cases where proper antenatal care and timely referral can prevent both perinatal and maternal morbidity and mortality.

In our study fetal risk factors associated with IUFD were mostly congenital malformations $(9.80 \%)$. We found four cases with CNS malformations and one case with multiple organs malformations. Detailed marital history, nutritional history, exposure to teratogens and history of febrile or viral illness could not be ascertained, this study being a retrospective study. Although chromosomal abnormalities and congenital malformations are unavoidable, routine screening and selective termination of pregnancies in such cases would reduce these deaths. Study by Anjali $\mathrm{C}$ et $\mathrm{al}^{8}$ found $11.5 \%$ and Singh $\mathrm{N}$ et $\mathrm{al}^{9}$ observed $9.45 \%$ cases of IUFD due to congenital malformation. Other risk factors with IUFD in our study were, prolonged PROM with chorioamnionitis (3.92\%), Preterm PROM (3.92\%), severe oligohydramnios (1.96\%), Severe IUGR (1.96\%), postdatism (1.96\%), placenta previa (1.96\%), abruption $(3.92 \%)$, retained twin $(1.96 \%)$ and severe burn $(3.92 \%)$.

Death of a well grown viable fetus is tragic enough but not knowing the cause of it can be more distressing. Unexplained fetal deaths in our study were $(11.76 \%)$. Anjali C et $\mathrm{al}^{8}$ found same in $19.5 \%$ while Singh N et al ${ }^{9}$ 
and Lamia Shaban et al $^{16}$ had observed $33 \%$ and $28 \%$ unexplained fetal deaths in their studies respectively. Knowledge about reason for the loss can help in taking measures to prevent recurrence in subsequent pregnancies.

In our study $41.17 \%$ cases came in advanced labor and delivered vaginally while $23.52 \%$ cases delivered vaginally after induction. Only $17.64 \%$ cases needed caesarean delivery. Study by Singh $\mathrm{N}$ et $\mathrm{al}^{9}$ had reported spontaneous vaginal delivery in $37.55 \%$ cases induced delivery in $51.01 \%$ and LSCS in $11.46 \%$.

Of all IUFD in our study $82.35 \%$ delivered were fresh and only $17.64 \%$ were macerated. Tamarkar $\mathrm{SR}^{13}$ had observed majority of stillborn to be non- dysmorphic. We observed $56.86 \%$ male and $43.33 \%$ female babies and previous studies also suggested that male fetuses are more likely to suffer from antenatal hypoxia (ante- or intra-partum). ${ }^{13}$ Post-delivery placental examination was normal in $78.43 \%$ cases while retro placental clots were seen in $17.64 \%$, which mostly were the cases of APH or $\mathrm{PIH}$.

Maximum puerperal complications noted by us were psychological upset in $56.86 \%$ cases. Postpartum hemorrhage occurred in $23.52 \%(n=12)$ cases, out of which 10 cases required blood transfusion. Maternal mortality occurred in four cases $(7.84 \%)$, reasons were; ruptured uterus with severe anemia with DIC (1), severe burn with septicemia (1), severe preeclampsia with HELLP syndrome with DIC, severe preeclampsia with atonic postpartum haemorrhage with DIC (1). Maternal mortality observed by Patel S et al ${ }^{10}$ was $1.2 \%$.

\section{CONCLUSIONS}

Lack of antenatal care is directly related to the socioeconomic and educational level of women. Health education toward stressing the importance of antenatal care, ante partum screening for congenital malformations and selective pregnancy terminations or and only for hospital delivery under supervision of appropriately trained personnel will go a long way in reducing a number of preventable fetal deaths.

Nothing is as sad and depressing as intrauterine death of a fetus for both parents and the obstetrician. Majority of fetal wastage can be prevented with health education, universal and improved antenatal care and encouraging hospital deliveries. Most of the IUFD are avoidable and treatable. Those IUFD which are unexplained are unavoidable. These patients need detailed genetic and microbiological studies for one or both partners. Such couples also need psychological counseling, nutritional advice and pre-pregnancy planning.

It is a well-established fact that adequate prenatal care is associated with better pregnancy outcome. However implementation of universal prenatal care is dependent on lot of factors like availability of health care facilities, skilled personnel, infrastructure and transport. Despite these efforts a lot more needs to be done to bring down IUFD rate to a minimum acceptable figure.

Funding: No funding sources

Conflict of interest: None declared

Ethical approval: The study was approved by the Institutional Ethics Committee

\section{REFERENCES}

1. Richardus JH, Graafmans WC, Verloove-Vanorick, SP. Mackenbach JP. The perinatal mortality rate as an indicator of quality of care in international comparisons. Med Care. 1998;36(1):54-66.

2. Clinical practice guideline: investigation and management of late fetal intrauterine death and stillbirth, institute of obstetrician and gynecologists, Royal College of physicians Ireland, and Directorate of strategies and clinical programmed, health service executive. October 2011-revised 2013; Version 1.0, guideline no. 4.

3. Estimates of mortality indicators-Census of India website-vital statistics. Chapter 4, pp 81, statement 51, 2012.

4. Jahanfar Sh, Ghiyasi P, Haghani H. Risk factors related to intra uterine fetal death in Iran: a case control study. Shiraz E-Medical J. 2005;6(3\&4):114.

5. ILu JR, Mccowan L. A comparison of the perinatal society of Australia and Newzealand-perinatal death classification systems and relevant condition at death stillbirth classification systems, Aust NZ Obstet Gynecol. 2009:49(5):467-71.

6. Goyal Lajya,D Parveen Rajori, Verbal Autopasy of 115 cases of Intrauterine fatal Death .Indian Journal of Public health research and Developement,Vol.4 Issue 1. 2013, Pg 147-152.

7. Bairwa M, Rajput M, Sachdeva S. Modified kuppuswamy's socioeconomic scale: social researcher should include updated income criteria, 2012. Indian J Community Med. 2013;38:185-6.

8. Choudhary A, Gupta V. Epidemiology of intrauterine fetal deaths: a study in tertiary referral centre in Uttarakhand. IOSR J Dent Med Sci. 2014;13(3):036.

9. Singh N, Pandey k, Gupta N, Arya A, Pratap C, Naik R. A retrospective study of 296 cases of intra uterine fetal deaths at a tertiary care centre. Int J Reprod Contracept Obstet Gynecol. 2013;2(2):141-6.

10. Patel S, Thaker R, Shah P, Majumder S. Study of causes and complications of intra uterine fetal death (IUFD). Int J Reprod Contracept Obstet Gyneco. 2014;3(4):931-5.

11. Informing equitable health policy reform: policy implementation assessment inspires action in Uttarakhand, India, 2010. Available at http://www.healthpolicyinitiative.com/Publications/ 
Documents/1156_1_Uttarakhand_Final_Brief_FINA L_5_31_10_acc.pdf. Accessed on 25 February 2016.

12. Khashoggi TU. Epidemiology of intrauterine foetal deaths in Saudi Arabia: Kkuh experience. Biomed Res. 2005;16:59-64.

13. Tamrakar SR, Chawla CD. Intrauterine foetal death and its probable causes: two year experience in Dhulikhel Hospital, Kathmandu University Hospital. Kathmandu Univ Med J. 2012;10(4):44-8.

14. Korde NV, Gaikwad P. Causes of stillbirth. J Obstet Gynaecol India. 2008;58(4):314-7.
15. Kotweg FJ, Gordjin SJ, Timmer A, Holm JP, Ravise JM, Erwichh JJ. A placental cause of intrauterine fetal death depends on the perinatal mortality classification used. Placenta. 2008;29(1):71-80.

16. Shaaban A Al Saleh LA, Alwafi BM, Al Raddi RM. Associated risk factors with ante-partum intra-uterine fetal death. Saudi Med J. 2006;(1)76-9.

Cite this article as: Patel S, Sirpurkar M, Patel MS. A retrospective study to evaluate etiological factors associated with intrauterine fetal death at tertiary referral centre. Int J Reprod Contracept Obstet Gynecol 2016;5:970-5. 